\title{
Transportation Planning: A Comparison Between Moroccan and Spanish Decision Making Process
}

\author{
Ait Boubkr Asmaa, ${ }^{*}, 1,2$, Gaboune Brahim ${ }^{1}$ and Avel-Li' Blasco Esteve ${ }^{2}$ \\ ${ }^{I}$ Laboratory of Management Research, Doctoral Studies' Center on Law and Economy, University Mohammed- $V$ - \\ Souissi, Rabat, Morocco \\ ${ }^{2}$ Public Law's Department, University of the Balearic Islands, 07122 Mallorca (Illes Balears), Spain
}

\begin{abstract}
Morocco's urban transport sector was characterized until recently by major institutional, regulatory, and operational weaknesses, as a result, public transport systems still perform poorly and are not responsive to the changing demands of the population. In this area, the planning of transport systems (in the context of the overall development of urban regions) takes an increased significance. The Government has thus embarked on a broad program of activities aimed at systematically addressing sector issues, particularly the structural issues that are at the core of the current inefficiencies. In fact, it is important to understand the functioning of decision making processes with respect to transport planning.

In order to do so, a comparative study of Moroccan and Spanish decision making processes is done. The paper deals with the differences and similarities of Moroccan and Spanish decision making process in transportation infrastructure planning following the issues cited in Procedures for Recommending Optimal Sustainable Planning of European City Transport Systems (PROSPECTS) Decision Makers' Guidebook (DMG). We have compared the two cases against each other with respect to these issues to identify examples of good practice for the Moroccan case.
\end{abstract}

Keywords: Transportation planning, decision making process, sustainability.

\section{BACKGROUND}

The transport system can be considered as a sociocultural complex adaptive system [1], in which the interchanges between their elements may result in significant changes in the nature of the elements themselves with important consequences for the system as a whole [2]. Besides this complexity, the transport system is also influenced by contextual elements [3], also referred to as development variables [2], which are part of other interrelated systems, such as the environment or the economy. Consequently, decisions on transport planning processes are unavoidably complex. Moreover, decision making today is no longer seen as an intellectual process, but as a socio-political and organizational process, whereby the interest has shifted from the quality of the decision towards the quality of decision making [4], and the knock-on effects of any one decision may be difficult to predict and are sometimes counter-intuitive.

However, there is ample evidence that current transport systems around the world are unsustainable, in terms of their growing levels of congestion, pollution, fuel consumption and accidents, the adverse effects on the economy, and the increasing polarization of opportunities to travel. Increasingly, too, cities are concerned with the wider impacts of transport on other social issues, such as health, education

*Address correspondence to this author at the Laboratory of Management Research, Doctoral Studies' Center on Law and Economy, University Mohammed-V-Souissi, Rabat, Morocco;

Tel: +34666166894/+212673245656;

E-mails: asmaa.aitboubkr@gmail.com, asmaa63@yahoo.fr and social inclusion. What is best will depend very much on the emphasis which a city gives to reducing congestion, improving the environment, stimulating healthier lifestyles, strengthening the economy and protecting those who are disadvantaged. In this context, the reform of the transport sector has been recognized as a priority by the Moroccan Government. In fact, Moroccan urban transport sector was characterized until recently by major institutional, regulatory, and operational weaknesses. The Government has thus embarked on a broad program of activities aimed at systematically addressing sector issues, particularly the structural issues that are at the core of the current inefficiencies. In order to support the ongoing reform, the Moroccan Government and the European Union (EU) have elaborated a comprehensive set of measures to be supported under the budgetary support program, and the World Bank has earmarked US\$140 million to improve urban transportation efficiency in Morocco (for 2010-2013).

To further analyze the newly adopted transport planning policy and its decision making process, a comparative study with Spain has been undertaken. Spain constitutes an interesting case for a comparative study in an EU context. It has received substantial support from European Funds for its infrastructure development in the last two decades. This was particularly the case for transport, in which Spain received a third of the total investment in improving the transport network over the periods 1994-99 and 2000-2006 [5], contributing in an average of some $20 \%-30 \%$ of the Ministry of Public Works and Transport infrastructure expenditure [6]. The result has been that Spain has reduced its disparities in network endowment with the rest of the EU significantly. 
This fact, along the progressive convergence of Spanish Gross Domestic Product (GDP) per capita values has meant that this financial support will be substantially reduced in the near future. The paper deals with the differences and similarities of Moroccan and Spanish Decision Making Process in transportation infrastructure planning following the issues cited in PROSPECTS Decision Makers' Guidebook [7]. These cases have been compared in order to identify examples of good practice for the Moroccan case.

\section{METHODOLOGY AND STUDY STRUCTURE}

Comparative analysis is usually broken down into two types according to whether the aim is to explain differences or similarities. A more elaborate classification is set out by Tilly [8] who distinguishes four types: individualizing, universalizing, variation-finding and encompassing as referred in [9]:

- Individualizing comparison contrasts 'a small number of cases in order to grasp the peculiarities of each case'

- Universalizing comparison 'aims to establish that every instance of a phenomenon follows essentially the same rule'

- Variation-finding comparison seeks to 'establish a principle of variation in the character or intensity of a phenomenon by examining systematic differences between instances'

- $\quad$ Encompassing comparison 'places different instances at various locations within the same system, on the way to explaining their characteristics as a function of their varying relationships to the system as a whole' e.g. as in Wallerstein's world system analysis.

In this paper, we adopt the individualizing approach of comparative analysis which involves discovering how different two cases are. This approach is a necessary precondition of comparative study since it provides an accurate grasp of the specificities of cases. In the following pages, we present each of the two cases in terms of some principal issues cited explicitly in the Decision Makers' Guidebook [7], as the following structure:

- $\quad$ Approaches to decision making adopted and public participation;

- Objectives;

- Barriers to implementation

Other issues considered in the Decision Makers' Guidebook concern policy instruments, appraisal and modeling are not taken under consideration in this paper.

\section{DECISION MAKING PROCESS IN TRANSPORT PLANNING: THEORETICAL BACKGROUND}

The planning process of a transport infrastructure Plan entails a high degree of complexity. At this level, decision making is the result of an interaction between many actors influenced by a complex environment, and the definition of transport planning objectives may arise conflicts between the different stakeholders involved [10].

However, the inclusion of the "sustainable development approach [11] in transport planning processes caused a shift in transport planning objectives towards strategic policy goals, such as network efficiency, cohesion or environmental issues. This structure of strategic objectives is intimately linked with the increased inclusion of transport sustainability issues [12] and [13] into planning framework.. This section discusses the inclusion of the concept sustainability in transport planning, and, the theoretical background of decision making process, as it was identified in PROSPECT guidebook.

\section{A. Sustainable Development and Transport Planning}

The concept of sustainable development [14] emerged in the 1980s in the environmental field, and was originally named as "Environmentally Sustainable Development" (ESD). It was triangular framework [11] representing three dimensions: economic, social, and environmental. It was in the 1990s when the concept of sustainable development was introduced as an overall goal for transport sector. Since then, the terms used to refer to the three general sustainability objectives were adapted to suit the specific characteristics of the transport problem under consideration. Nowadays the term 'sustainable transport' is a generally accepted principle in transport planning processes [12, 15-17]. The three main basic goals of the Common Transport Policy (CTP) in EU are: competitiveness (economic objective), cohesion (social objective) and environment (environmental objective).

- The economic objective refers to the contribution of a transport initiative to increase the overall productivity of economic activities, in terms of increasing opportunities for new relations and bridging existing bottlenecks [18]. Therefore, this objective is intimately linked with the impact of transportation costs in economic performance [19].

- $\quad$ The social objective, at the project level, refers to objectives such as accident reduction, noise abatement, or local emission reduction [20] and [21]. In broad terms, it refers to cohesion, which means a reduction of economic disparities [10] or differences of economic and social welfare [22] between regions and groups.

- In the past few decades there has been an increased concern for assessing the environmental effects of transport and developing mechanisms to report their evolution. The transport sector is the primary driver of the growth in total energy consumption, which is likewise directly linked with total emissions [23] despite the important efforts devoted to environmental abatement policies, the high rate of increase in transport demand is outstripping the rate of improvement in environmental technology for transport [24].

\section{B. Decision Making Process: An Overview}

Early studies of policy making highlighted two extreme approaches to decisions: a rational, analytical approach which leads inexorably to the right solution, and less organized approach, often called "muddling through", in which objectives are never specified, remedial action is taken when it becomes essential, and more important decisions are dependent on the power struggles between interest groups. 
The EU-funded project PROSPECTS - Procedures for Recommending Optimal Sustainable Planning of European City Transport Systems (PROSPECTS 2000-2003)investigated the decision making processes for urban transport planning, and identified an decision making process for sustainable transport planning in the European context. This process, which incorporated results from a number of previous EU research projects, was described in detail in " a Decision Makers Guidebook" (DMG) [7]. The DMG was designed to help all those involved in decisions on land use of transport, in cities throughout Europe, whether they are politicians, professional advisers, stakeholders or individual citizens.

The DMG [7] identified three broad approaches to decision making in Europe: vision-led; plan-led; and consensus-led. Vision-led approaches usually involve an individual political leader (such as a mayor) having a clear view of the future form of city, and pushing through the policy instruments needed to achieve that vision.

Plan-led approaches involve specifying objectives and problems (with problems being defined as failures of current or predicted future conditions to meet the objectives); adopting an ordered procedure that identifies possible solutions to those problems; and selecting those which perform best. This procedure will typically involve the use of formal appraisal methods (such as cost-benefit analysis or multi-criteria analysis), which receive input from computer models that predict the future impacts of alternative policies. Underpinning a plan-led approach, an "ideal strategy development process" can be defined. This process includes the stages of: definition of objectives, performance indicators and targets; the identification of barriers to implementation and how to overcome them; the formation of packages of measures; and the use of appraisal and modeling methods to predict the extent to which any package of measures meets the defined policy objectives (Fig. 1).

Consensus-led approaches involve discussions between the stakeholders to try to reach of the stages in formulating a strategy. All strategy development should take place within an ongoing context of public participation, which can be classified according to the following levels (ranging from the less active to the more active): information provision; consultation; deciding together; acting together; and supporting independent stakeholder groups. A distinction can be made between formal statutory consultation methods and informal participation methods. A large number of the latter have been implemented in various European cities and, in general, a successful public participation strategy will combine a wide range of such methods.

In practice, European cities differ in the ways in which they make decisions, but their approaches have often developed over time. In PROSPECTS DMG [7] over 50 Cities in Europe were asked which approach they were using, in terms of: vision-led; consensus-led or plan-led. A summary of their responses in shown in Fig. 2). It can be seen that most of the cities adopt a mixed approach, particularly either a plan/consensus mix or a vision/plan mix. Of these cities, 19 were "large", defined as those with a population greater than 250,000 . Of these large cities, 14 had an approach which was a mix of plan- led and consensus-led, whilst there was more variation in the type of approach amongst med. Nevertheless, there are some obvious pitfalls to each approach. A vision-led approach is critically dependent on the individual with the vision. If he or she leaves office, it may prove very difficult to avoid completely abandoning the strategy. A plan-led approach can become unduly dependent on professional planners, who may lose sight of the needs of ordinary citizens, in particular those not associated with powerful groups and who thus cannot make their voices heard. A consensus-led approach may, unless agreement can be reached in a reasonable length of time, lead to unacceptable delay and inaction.

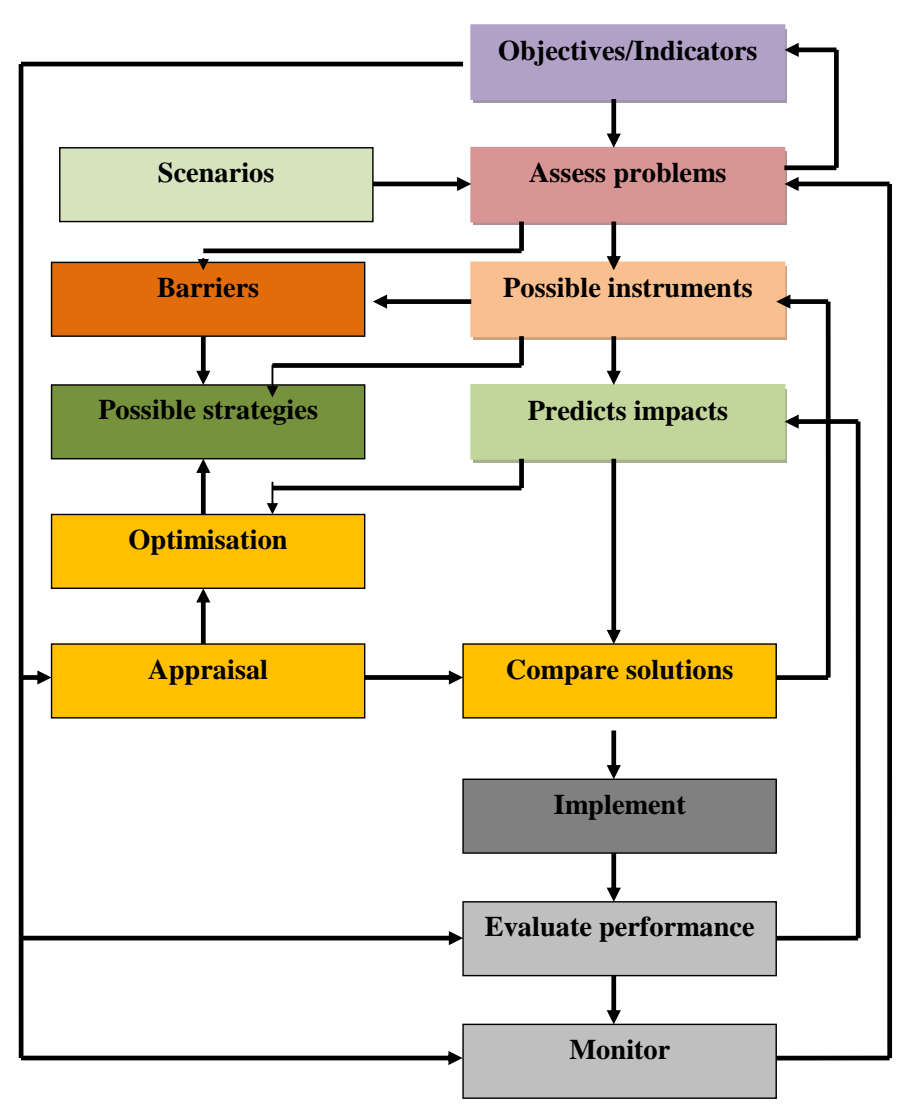

Fig. (1). The "ideal" Decision Making process [25].

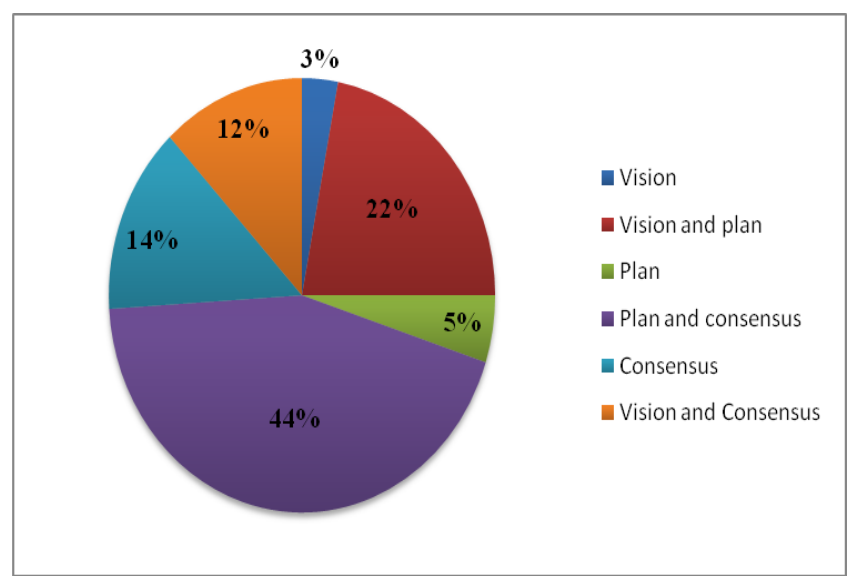

Fig. (2). European cities decision making approaches [25]. 


\section{MOROCCAN AND SPANISH NEW APPROACHES OF TRANSPORTATION POLICIES}

There is no single solution to urban transport problems, and to achieve sustainability in a transport system, the DMG has identified four key elements: reducing the need to travel; reducing car use, improving public transport; and improving efficiency of the road network.

In developing transport strategy, it is essential to be clear what the strategy is designed to achieve. Objectives are broad statements of the improvements which a city is seeking in its transport system. It is important that decision makers determine the objectives which they wish to pursue.

Seven objectives relating to a sustainable transportation are suggested in the Decision Makers Guidebook, including protection of the environment, liveable streets and neighbourhoods, safety, equity and social inclusion, economic efficiency, contribution to economic growth, and intergenerational equity. Usually, it is not possible to satisfy all of the objectives which may be desirable, as some of them will conflict. Therefore, priorities between objectives are important. In this section, we will compare the new transportation strategies objectives of both studies with those proposed in the guidebook.

\section{A. Moroccan Transport Sector Reform}

In Morocco, public transport systems perform poorly and are not responsive to the changing demands of the population [25]. The road infrastructure and the management of traffic are also lagging behind, and congestion is increasing fast, particularly in Casablanca, the economic capital, where it is now perceived as a threat to the city's competitiveness and economic growth prospects. Air quality has deteriorated sharply, in great part due to transport, and some key social needs are not adequately addressed. Morocco's urban transport sector does not serve its population and economy as well as it should. Inadequate supply of public transport services is one of the main symptoms of this poor performance. Indeed, the supply of bus services in Morocco's main cities is equivalent to roughly one third of the supply in most middle income countries in Latin America and East Asia. As a result, inefficient taxi services have filled the gap left by buses, and private transport modes (mainly cars) are increasing fast. For poor people, walking is the main mode of transport, which heavily constrains their access to jobs and public services. The other main symptom is the growing congestion of the urban road network. In Casablanca, Morocco's largest city, studies carried out in 2004 have shown that close to $60 \%$ of the primary street network was highly congested. Congestion was also projected to double from 2004 to 2019 if present trends continued, and the average speed of public transport vehicles and cars was expected to be reduced by $40 \%$ and $20 \%$ respectively. Congestion affects people, commerce and manufacturing, and all aspects of economic and social life. It is a threat to the productivity of Moroccan cities. There are many structural weaknesses that explain this situation; the World Bank [25] has elaborated a list of indicators to assess the sector performance, as shown in Table 1.

The Government has thus embarked on a broad program of activities aimed at systematically addressing sector issues the reform of transport sector is organized under three main pillars: (1) improving the sector's governance; (2) improving the efficiency and developing the supply of urban transport services and infrastructure; and (3) improving the environmental and social sustainability of urban transport.

1) Improving the sector's governance: The establishment of urban transport planning and management agencies for each large urban area is a cornerstone of the Government's program. These agencies would be responsible for preparation and monitoring of the cities' multimodal urban transport strategies, selection of investment priorities, organization and management of public transport, and traffic management and parking. They would comprise both a decision making body at the political level and a technical structure. The recent amendments to the Charte Communale have provided legal options to the local governments to set up these agencies and have strengthened the role of the Ministry of Interior in inducing them to move ahead.

The Government's program includes actions so that each large urban area can have in the near future a sound multi-modal urban transport strategy and priority investment plan.

2) Improving the efficiency and increasing the supply of urban transport services and infrastructure: The Government has recognized the key role of public transport and the need to ensure that it efficiently serves the population's demand in volume as well as in quality and contributes to making urban transport more climate friendly. For this, the Government's program includes the promotion of technical, organizational and regulatory measures as well as investments which will develop capacity and supply of services ensure that costs are consistent with the customers' ability to pay, and improve coordination between various public transport modes.

3) Improving the environmental and social sustainability of urban transport: The Ministries of Finance and Interior, and local public authorities, are making significant investments in alternative public transport modes such as the light rail transit lines in Casablanca and Rabat-Sale. The Government's program includes establishing the necessary institutional and regulatory framework for dealing with accessibility issues, providing adequate technical tools to stakeholders, particularly the municipalities, and raising awareness of all concerned. The Government will also define accessibility criteria, and implement pilot accessibility projects in cities in Morocco.

\section{B. Spain: New Approach for Infrastructure Policy}

In Spain, the public transport infrastructures have experienced strong growth in the last fifteen years. This growth is characterized by its nature and most recent causes, specifically [26]:

- The supply of services has increased in response to an increase in demand which in turn is influenced by demographic growth in the principal cities; 
- Urban development has taken place in many cities, including in some no bigger than average (This development has shaped wide metropolitan areas in which an emerging set of specialization).

The overall role of public transport system is directly influenced by the size of the metropolitan area considered. To highlight, the increasing importance of the public transport in big cities like Madrid, Barcelona and Malaga due to the development of new transport networks. The high use of the bus system characterizes most Spanish metropolitan areas.

The transport policies have combined four key principles for many years. An integrated public transport system has been developed, covering fares, services and the administrative framework. There has been an impressive investment in transport infrastructure, including commuter rail services, expansion of the metro system (with $120 \mathrm{~km}$ of new lines in the last ten years), innovative infrastructure, and the development of park and ride interchanges. The quality of public transport has been enhanced, encouraging and assisting undertaking to renew their fleets and introducing more comfortable, less polluting vehicles.

The main innovation in Spain related to urban public transport of the past few years has been the creation of the transport "consortia" that run the urban transport as an integrated system of the conventional modes. This led to the introduction of new transportation infrastructure such as new tram and light-rail lines and buses that run on gas (they already make up $10 \%$ of the fleet), and on hydrogen (still in the experimental phase). The history of these consortia is quite recent, especially in relation to the integrated supply of urban transport which only fully materialize when the unified fare systems were introduced. Actually, the main planning instrument in place is the Plan Estratgico de Infarestruturas y Transporte 2005-2020 (PEIT). The subsectorial programs and specific projects in each subsector situate both the objectives and the deadline for instruments in the intervening years (2005-2020).

The PEIT objectives have been structured in four fields, which have been summarized below [6]:

- To enhance the system's efficiency in terms of the quality of the services actually provided, and to deal with the needs for the mobility needs of people and flows of goods by developing an integrated transport system, optimizing use of existing infrastructures and promoting conservation and maintenance of infrastructure assets.

- $\quad$ To enhance social and territorial cohesion by ensuring equitable conditions of accessibility throughout the country and identifying the potential beneficiaries of infrastructure and transport policy, avoiding regressive transfers of income.

- To contribute to the system' general sustainability by compliance with the international commitments in the European environmental provisions, in particular in relation to GreenHouse Gas (GHG) emissions.

- To promote economic development and competitiveness, by enhancing the role of Spanish urban and metropolitan areas, reinforcing crossborder links and promoting Research \& Development programs and technological advices.

The PEIT establishes a set of guidelines to achieve these objectives. In relation to territorial policy objectives, the focus is set on the achievement of a 'territorial balance and enhanced accessibility'. For this purpose, the development of land transport networks should aim at correcting 'the radial systems of the past, establishing connections with the other networks, limiting territorial concentration of high-capacity infrastructures and adjusting services to the intensity of flow' [6]. Furthermore, it also demands the development of 'cross-

Table 1. Moroccan Transport Weaknesses [25]

\begin{tabular}{|c|c|}
\hline Indicator & Baseline \\
\hline Efficient planning, coordination, and management of the urban transport sector. & No bus route network restructuring Plan. \\
\hline $\begin{array}{l}\text { Effective coordination of policies and programs among the main Government } \\
\text { departments involved in the urban transport sector. }\end{array}$ & $\begin{array}{c}\text { The National Commission for urban displacements (CNDU) has just } \\
\text { been established and has not met. }\end{array}$ \\
\hline $\begin{array}{l}\text { Effective Central Government support provided to local authorities on urban transport } \\
\text { issues. }\end{array}$ & $\begin{array}{c}\text { No convention has yet been signed by the Ministry of Interior and } \\
\text { local governments. }\end{array}$ \\
\hline $\begin{array}{l}\text { Sufficient urban transport expertise is available in the cities that have carried out or } \\
\text { launched the preparation of their urban transport strategies and priority investment plans. }\end{array}$ & No expert and no city have yet benefitted from the training program. \\
\hline $\begin{array}{c}\text { Improved quality and quantity of bus services in the agglomeration of Rabat-Sale- } \\
\text { Temara. }\end{array}$ & No service supplied at the outset. \\
\hline Improved quality and quantity of bus services in the agglomeration of Casablanca. & 1.9 seat-km supplied in 2009. \\
\hline $\begin{array}{l}\text { The procurement process for concessioning public transport services is in line with } \\
\text { international best practice. }\end{array}$ & New regulation on procurement procedures not applicable \\
\hline $\begin{array}{l}\text { Government financial support is allocated to those urban transport investment projects } \\
\text { with superior economic and social returns. }\end{array}$ & Eligibility criteria not yet applicable \\
\hline Effective vehicle inspection and monitoring systems are in place. & $\begin{array}{c}1.1 \text { million car inspection visits have had their report issued through } \\
\text { the automated electronic process in } 2010 .\end{array}$ \\
\hline $\begin{array}{c}\text { Accessibility for persons with limited mobility has been mainstreamed in urban transport } \\
\text { projects and awareness has increased. }\end{array}$ & No city with accessibility project Component. \\
\hline
\end{tabular}


border links between Autonomous Communities with land borders and the regions of Portugal and the South of France to channel their economic and cultural relations'. However, it stresses that this development should follow 'specific criteria avoid their de facto transformation into alternative corridors for large transport flows' [6].

\section{DECISION MAKING APPROACHES ADOPTED}

\section{A. Decision Making Process, as Identified in Morocco}

The three approaches was adopted too, but there implementation suffers from some insufficiencies in regarding to participation approach which is used only in the front-end project phase.

1. Vision-led approach: Urban transport was a major theme of the National Urban Development Symposium opened by H.M. the King Mohammed VI in January 2007 and has remained since then a key part of the urban sector agenda.

2. Plan-led approach: Decision about transportation infrastructures projects are made step by step, along a complex process of planning and design. This process integrates economic and environmental appraisals.

For transportation planning, the studies are developed in three phases. In the first one (Phase A) the study area is characterized, according to physical, environmental, territorial criteria. This activity allows identifying a number of broad-brush routes (corridors) that are potentially compatible with this set of criteria.

In the second stage (Phase B), more detailed routes and designs are introduced in each of the broad-brush routes selected in the previous phase. A quantitative characterization of all these alternatives is made, considering the following points of view:

- $\quad$ Economic (capital costs, Cost Benefits Analysis...); Functional (traffic forecasts, safety...);

- Environmental (expected residual impacts after mitigation measures);

Spatial (relationships with urban and land use planning, effects on other infrastructures).

A Mutli criteria analysis is carried out using these four groups of criteria. The study, including the recommended and the others alternatives, is then submitted to the entity responsible of the project (it can be administration or agency; it depends on the city in which the project is going to be implemented).

3) Participation and stakeholders involvements: Traditionally, transport decisions have been made by politicians, advised by expert professionals. However, life is now much more complicated. On the one hand, there is an increasing demand for public participation, in particular concerning social groups who have traditionally been excluded from the policy formulation process. On the other hand, very few cities are "islands", so policies are influenced by neighbouring towns and cities. This influence may also be determined by regional policies, national government and, increasingly, European policy.
Furthermore, fewer policy decisions can now be taken solely by government, even if influenced by public participation. The private sector and semiprivate agencies are increasingly responsible for public transport, road construction and land use decisions.

In Morocco, a vigorous debate has taken place on the questions of transportation since 2006. This debate has taken place not only in the sector context but also as part of the Government's on-going broader review of urban development policies and processes.

The Government has also organized numerous events to debate urban transport policies in recent years. These have been reported in the media, sometimes to a wide audience. The most important event was the January 2008 Skhirat international conference, which brought together most of the sector's stakeholders, not only elected officials, senior staff, and technical experts from local and central governments, including three ministers, many governors, and mayors, but also transport specialists from academia and consulting firms, transport operators, international donors, and civil society participants. The 2008 Skhirat conference, which represented a key step in the formulation of the Government strategy, was attended by about 300 participants with a wide diversity of interests, expertise, and constituencies.

Since then, other symposia have provided opportunities for stakeholders to debate urban transport sector issues and priorities. This was the case in particular of the 2009 Agadir seminar on decentralized cooperation and the 2010 Africits conference in Marrakesh. The preparation of urban transport master plans in Casablanca, Rabat-Sale-Temara, and Marrakesh has also included extensive user surveys which have provided a wealth of information, generally differentiated by social background, on the way people use urban transport, their expenditures, their needs, and their desire for improvement. Surveys in Casablanca have especially emphasized the poor performance of public transport.

\section{B. Spanish Decision Making Process}

As mentioned earlier, there is a wide diversity in the types of decision making used in Europe, i.e, the balance between plan-led, vision-led and consensus-led approaches varies greatly between the European cities. The three approaches to decision making are in operation in Spain, but there has been a clear move from the "plan-led" to the "vision-led" approach (guidebook).

The Spanish Ministry of Transport was intending to recover long-term planning as "the tool by which to frame its medium-term actions, and to take on a public commitment in the pursuit of the policies for which it is responsible". Planning should, inter alia, be able to facilitate "Transparent decision making, widening the involvement in the process not just of the social-professional and financial sectors directly involved, but of the whole of society. Planning is a characteristic of a system of governance based on participation and the willingness of those responsible for public policies to account for their decisions and the results of such decisions to citizens" [27].

The Ministry of Transport (MoT) faced a paradoxical situation towards public involvement. On the one hand, it 
was thought to be highly necessary for the MoT to develop a wide consensus in the "need for change" and in finding the right "path towards sustainability".

The main mechanisms used for public involvement by the MoT included:

- Discussion of key transportation challenges (as identified by the technical MoT services in an initial document of diagnosis) within focus groups. The discussion was structured in two sessions: a session with the attendance of a balanced representation of the various stakeholders (including foreign experts in each particular field), and an open session hosted by leading transportation Universities in the country. The selected discussion themes included environmental goals in transportation, landscape and spatial development, economic development and transportation; development of intermodal systems for passengers and freight; sustainable urban mobility, and pricing. This procedure ended with a general meeting, with some 200 participants representing a wide array of stakeholders and interest. Frequent contacts with the media, presenting and justifying the planning approach, including a half day meeting of the technical team with a wide audience of journalists.

- Bilateral meetings with the nineteen regional transportation administrations in the country followed by a general discussion when the draft document was completed, before launching it for public enquiry.

- Internal consensus-building within the MoT - trying to conciliate modal approaches by creating a technical steering committee, which met several times - and with other Ministries - notably the Ministry of Environment, to adapt the procedure to the Strategic Environmental Assessment (SEA) Directive guidelines. "Formal consultation - initially for two months, finally reopened to include all the comments received.

The formal consultation, although legally limited to those aspects included in the SEA Directive, was opened to any other relevant aspects. Comments were submitted to extensive analysis, to give input to the final version of the plan.

\section{BARRIERS}

A barrier is an obstacle which prevents a given approach being implemented, or limits the way in which it can be implemented. The PROSPECTS DMG identifies four main categories of barrier:

- Legal and institutional barriers: These include lack of legal powers to implement a particular instrument, and legal responsibilities which are split between agencies, limiting the ability of the city authority to implement the affected instrument

- $\quad$ Financial barriers: These include budget restrictions limiting the overall expenditure on the strategy, financial restrictions on specific instruments, and limitations on the flexibility with which revenues can be used to finance the full range of instruments.
- $\quad$ Political and cultural barriers: These involve lack of political or public acceptance of an instrument, restrictions imposed by particular interest groups, and cultural attributes, such as attitudes to enforcement, which influence the effectiveness of instruments.

- Practical and technological barriers: While cities typically view legal, financial and political barriers as the most serious with respect to implementing land use and transport policy instruments, there may also be practical limitations. For land use and infrastructure these may well include land acquisition. For management and pricing, enforcement and administration are key issues. For infrastructure, management and information systems, engineering design and availability of technology may limit progress.

\section{A. In Morocco}

In Morocco, the main barriers are specially those related to Legal and institutional barriers. In fact, the most serious weakness is the lack of effective institutions in most large Moroccan cities for monitoring and evaluating the performance and development of urban transport and formulating and implementing government actions. Although many stakeholders are involved, including especially the municipalities, the other local governments (provinces and regions), and the de-concentrated services of the central government (first of all, but not exclusively, the Governors' offices - the Wilayas - and the urban development agencies), their responsibilities are fragmented and there are many gaps as well as overlaps. According to the main legal text, the Charte Communale (Law 78-00), the municipalities are in charge of urban transport. In addition, a major weakness for the long term is that there is in practice little coordination between urban transport development and the broader planning and investment decisions related to urban development and land use.

Although the importance of urban transport issues has been recognized at senior level, there was no structure until recently to coordinate the strategies and activities of the several ministries involved in the sector, particularly the Ministry of Interior (MI), the Ministry of Equipment and Transport (MET), the Ministry of Housing and Urban Development (MHUD), and the Ministry of Economy and Finance MEF). There was also limited capability for the Central Government to monitor progress in the sector and design and implement financial and technical support programs for the local authorities.

\section{B. In Spain}

The Environmental legislation which remains the sole formal legal reason to make progress in public involvement, and it remains being perceived as a "barrier" by a significant - although decreasing - number of transportation practitioners. Any other participation opportunities are considered as voluntarily or "graciously" given by the MoT. The need to pass specific legal obligations on transportation planning and public involvement is not perceived as a priority. Although opposition within the MoT to participation has considerably decreased, the lack of formal 
regulations weakens and slows down the reform process in the sector.

\section{IMPACTS OF THE ADOPTED APPROACHES}

It is difficult to state in advance what will be the effect of introducing a particular policy instrument or strategy. A transportation policy may have a wide range of impacts on demand and supply, some of them immediate and other arising as users change their habits. In the extreme, with land use policies, some effects may take a decade or more to occur. At the same time it's necessary to understand these impacts, not just on demand and supply, but on the economic competitiveness, territorial cohesion, and environmental sustainability.

\section{A. Spain}

The impacts are assessed with the support of the SASI (Swept Area Seabed Impact) model [26]. The SASI model is a recursive-dynamic simulation model of socio-economic development of 1330 regions in Europe. The model was developed to assess socio-economic and spatial impacts of transport infrastructure investment and transport system improvements. The impacts have been assessed for two scenarios, the Reference scenario and the Balanced Scenario. In the Balanced scenario projects are prioritised on the basis of their benefit-cost ratio and their contribution to specific objectives and needs (sustainability, regional disparity, and contribution to accessibility). Table 2 presents the impacts of the new transportation policy [26].

Table 2. Impacts of New Transportation Policy in Spain [26]

\begin{tabular}{|c|c|c|c|}
\hline \multirow{2}{*}{ Objective } & \multirow{2}{*}{ Indicator } & \multicolumn{2}{|c|}{ Scenario } \\
\hline & & Reference & Balanced \\
\hline \multirow{3}{*}{$\begin{array}{c}\text { Economic } \\
\text { Competitiveness }\end{array}$} & $\begin{array}{l}\text { Average speed of } \\
\text { interregional road trips } \\
(\mathrm{kph})\end{array}$ & 52.0 & $\begin{array}{c}52.4 \\
+0.8 \%\end{array}$ \\
\hline & $\begin{array}{l}\text { Average speed of } \\
\text { interregional rail trips } \\
(\mathrm{kph}\end{array}$ & 31.8 & $\begin{array}{c}32.5 \\
+2.4 \%\end{array}$ \\
\hline & GDP per capita (Euro) & 30,914 & $\begin{array}{c}1,021 \\
+0.3 \%\end{array}$ \\
\hline \multirow{2}{*}{$\begin{array}{l}\text { Territorial } \\
\text { Cohesion }\end{array}$} & $\begin{array}{l}\text { Primacy rate }(\%) \\
\text { population }\end{array}$ & 14.0 & $\begin{array}{l}14.0 \\
0.0 \%\end{array}$ \\
\hline & Primacy rate $(\%)$ GDP & 18.5 & $\begin{array}{l}18.4 \\
0.0 \%\end{array}$ \\
\hline $\begin{array}{l}\text { Environmental } \\
\text { sustainability }\end{array}$ & $\begin{array}{c}\text { Share of } \\
\text { interregional rail trips } \\
(\%)\end{array}$ & 30.9 & $\begin{array}{c}32.1 \\
+3.9 \%\end{array}$ \\
\hline
\end{tabular}

Table 2 indicates that the overall impact of the PEIT in Spain is relatively modest but not negligible. In absolute terms, the transport infrastructure improvements of the policy scenarios increase the average income in Spain by 170 Euro per capita per year. This is mainly due to the significant volume of rail investment.

The impacts on the cohesion indicators, which reflect the impact of the transport policy on the spatial structure of the country, are negligible. Although (not shown in the table) no significant differences between the scenarios in the two primacy rates can be detected. The environmental effects in terms of increased rail share are significant.

\section{B. Morocco}

In Morocco, there's a lack of data and indicators that would allow evaluating the impacts of the new transportation strategy due to the absence of a "transport observatory". However, the World Bank [25] had assessed some social and environmental impacts.

Social impacts: The World Bank [25] concluded that the transportation reforms supported by Moroccan Government are largely positive for the marginalized populations of urban centers. In particular, low revenue groups in peri-urban areas in need of efficient and cost contained public transport services, as well as individuals with accessibility needs, stand to benefit from the reforms. With the emergence of specialized urban transport planning and management agencies in large urban areas, urban transport planning will be much better based on full consideration of the needs of groups lacking private transport opportunities. This will include the amelioration and/or extension of affordable transport options, especially in public transport. However, the main negative impact of the reform concerns job losses deriving from restructuring of bus systems in Rabat and Casablanca, which entails the discontinuation of private bus operators' services following the transfer of bus operations to a single operator in each city.

Environmental impacts: it is estimated that the new transportation approach' measures would reduce GHG emissions by about 400,000 Tons/year. These reductions will primarily result from the implementation of the vehicle inspection centers' reforms (GHG emissions reduction of about 350,000 Tons/year) and the restructuring of bus operations in Rabat and Casablanca (GHG emissions reduction of about 50,000 Tons/year in accordance with a very conservative methodology). Vehicle inspection centers' reforms will improve the quality and regularity of vehicle inspections, which will in turn lead to an improved maintenance and operations of the existing vehicle fleet in Morocco, and an improved quality of imported secondhand vehicles. Meanwhile, the restructuring of bus services will improve buses' technical quality and efficiency of operations. Both measures will have a large effect on fuel efficiency and GHG emissions.

\section{DISCUSSION AND CONCLUSION}

Three elements within the decision making process have been highlighted in this paper: strategy approaches, objectives and barriers. There is no simple recipe for making good decisions. The appropriate style of decision making varies according to the particular situation.

The two countries adopt a mix of vision, plan-led and consensus-led approaches as shown in Table 3. Spanish's approach has changed over time, with a move away from planning towards a vision-led emphasis. Morocco's approach is more strongly vision-led. Increased emphasis is being placed on consensus-building among stakeholders, and wider consultation is a key element in its approach. Plan-led approach is based heavily on the availability of data and the 
possibility of making predictions. In Morocco, data is less available and detailed predictions are harder to make.

In term of transportation objectives, the concept of sustainability, and the related necessity of taking environmental issues into consideration, needs more weight in political decision making in Spain and especially in Morocco. Both countries does not have a clearly stated set of objectives, but is principally concerned with problems caused by traffic growth and economic growth, as shown in Table 4.

Table 3. Decision Making Approaches

\begin{tabular}{|c|c|c|}
\hline & Morocco & Spain \\
\hline \hline Vision-led & $\checkmark$ & $\checkmark$ \\
\hline Plan-led & $\checkmark$ & $\checkmark$ \\
\hline Consensus-led & $\checkmark$ & $\checkmark$ \\
\hline
\end{tabular}

Table 4. Current Priority of Objectives in Morocco and Spain

\begin{tabular}{|c|c|c|c|}
\hline \multirow{2}{*}{ Objectives } & \multicolumn{3}{|c|}{ Priority } \\
\cline { 2 - 4 } & High & Medium & Low \\
\hline \hline Economic efficiency & $*$ & $\checkmark$ & \\
\hline Protection of the environment & & $* \checkmark$ & \\
\hline Liveable streets & & & $* \checkmark$ \\
\hline Safety & & $* \checkmark$ & \\
\hline Equity and social inclusion & $\checkmark$ & & $*$ \\
\hline Economic growth & $\checkmark$ & $*$ & $* \checkmark$ \\
\hline Future generations & & & \\
\hline Spain. & & & $*$ \\
\hline
\end{tabular}

Most of the barriers of implementation in Morocco are inter-related with the existing political system and have a long tradition, and in order to make more informed decisions regarding transportation issues, there is a need both for good project management and also the careful management of stakeholder relations.

These days, fewer decisions can be made exclusively by government agencies, and less public money is available for local authorities to implement transport projects. Private investors and operators are becoming more involved in public transportation projects, in new road construction, and in land use planning and building design. At the same time, the users, businesses and residents that are affected by these various projects demand a greater involvement in the decision making process, as part of a move towards societies that are based on governance models of participatory democracy.

This has two general implications for the way in which transport decision making is approached. First, due to the growing complexity of the issues to be addressed in the course of designing and implementing transport projects, there is a requirement for improved and more flexible project management techniques. Second, there is a growing belief that communities would support transport schemes more readily if they were more actively involved in designing them. They would better understand the need for the project and perhaps be more willing to accept compromises, and they would be able to suggest ways in which the proposals could be better adapted to meet their local needs. In short, they would 'own' the scheme, instead of regarding it as having been 'imposed' on them from above.

\section{ACKNOWLEDGEMENT}

None declared.

\section{CONFLICT OF INTEREST}

None declared.

\section{REFERENCES}

[1] W. Buckley, Sociology and Modern Systems Theory. Prentince Hall, Oxford, England, 1967.

[2] C. Rehfeld, "Transport infrastructure investments and decision support systems," Phd. thesis, Technical University of Denmark, Lyngby, 1998.

[3] D. Banister, D. Stead, P. Steen, J. Akerman, K.D.P. Nijkamp, and R. Sheicher-Tappeser, "Scenario building and methodological frame- work," In: Eur. Transp. Policy Sustain. Mob. Conf. London, 2000, pp. 111- 118.

[4] H. Voogd, "The changing role of evaluation methods in changing planning environment: some dutch experiences," Eur. Plann. Stud., vol. 5, no. 2, pp. 257-266, 1997.

[5] European Science and Technology Observatory (ESTO), "Policy support tools for transport issues," Joint Research Center, Patent 21393 EN., 2004.

[6] PEIT, Plan Estratégico de Infraestructuras y Transportes 2005-2020. Madrid, Dept. Transp., 2005

[7] A. May et al. "PROSPECTS-A Decision Maker's Guidebook. Methodological Guidebook",2005, pp 54. Available: http://www.ieelibrary.eu

[8] C. Tilly, Big Structures, Large Processes, Huge Comparisons Russell Sage Foundation, New York, 1984.

[9] C.G. Pickvance, "Four varieties of comparative analysis," J. Hous. Built Environ., vol. 16, pp. 7-28, 2001.

[10] J. Bröcker, R. Capello, L. Lundquist, J. Rouwendal, N. Schneeklo th, A. Spairani, M. Spangenberg, K. Spiekermann, D. van Vuuren, R. Vickerman and M. Wegener."Territorial Impact of EU Transport and TEN Policies" the European Spatial Planning Observatory Netwotk, 2004. Available: http://www.espon.eu

[11] I. Serageldin, Sustainability and the wealth of nations. first steps in an ongoing journey, Environmentally Sustainable Development Studies and Monographs, World Bank, Washington, D. C, vol. $5,1996$.

[12] D.L. Greene and M. Wegener, "Sustainable transport," J. Transp. Geograph., vol. 5, no. 3, pp. 177-190, 1996.

[13] OECD, Towards Sustainable Development-Environmental Indicators. Paris, France, 1998 Available: www.oecd.org.

[14] World Commission on Environment and Development, "Our Common Future”. Patent: A/42/427, New York, 1987.

[15] P. Nijkamp, "Roads toward environmentally sustainable transport," Transp. Res. A., vol. 28A, no. 4, pp. 261-271, 1994.

[16] K.J. Button and E. Verhoef, "Transport at the edge of mobility and sustainability," In: Transport Networks in Europe: concepts, analysis and policies, eds.,P. Nijkamp and H. Primus 1998.

[17] H. Lauridsen, Strategic transport planning evaluation-the scandinavian experience, In: Transport Projects, Programmes and Policies: Evalua-tion needs and capabilities, 2003.

[18] G. Chatelus and A. Ulied, Union Territorial Strategies linked to the Trans-European Transportation Networks (UTS, Patent: DG VII, 1996.

[19] SACTRA "Standing Advisory Committee on Trunk Road Assessment, Transport and the economy”. The Stationnery Office , London, 1999.

[20] A.L. Bristow and J. Nellthorp, "Transport project appraisal in the european union," Transp. Policy, vol. 7, no. 1, pp. 51-60, 2000.

[21] P. Mackie and J. Nellthorp, Transport appraisal in a policy context, In: Transport Projects, Programmes and Policies: Evaluation 
needs and capabilities, 2003.

[22] C. Hey, P. Nijkamp, S. Rienstra, and D. Rothenberger, "Assessing scenarios on european transport policies by means of multicriteria analysis," In: Project and Policy Evaluation in Transport, 2002.

[23] European Environment Agency, "Energy and environment in the european union. tracking progress towards integration,", Patent. 8/2006, Copenhagen, 2006.

[24] D. Stead, "Transport intensity in Europe: indicators and trends," Transp. Policy, vol. 8, no. 1, pp. 29-46, 2001.
[25] World Bank, "Implementation status \& results morocco urban transport sector," Morocco, Patent. ISR3533, 2011.

[26] European commission, "Study on strategic evaluation on transport investment priorities under structural and cohesion funds for the pro-gramming period 2007-2013," Patent 2005.CE.16.0.AT.014, SPAIN, 2005

[27] OECD, "National systems of transport infrastructure planning," European Conference of Ministers of Transport, Round Table 128, Paris, 2005. Available: www.oecdbookshop.org

(C) Asmaa et al.; Licensee Bentham Open.

This is an open access article licensed under the terms of the Creative Commons Attribution Non-Commercial License (http://creativecommons.org/licenses/by-nc/ $3.0 /$ ) which permits unrestricted, non-commercial use, distribution and reproduction in any medium, provided the work is properly cited. 